\title{
Tourism Marketing of the Hakka Genealogical Digital Archive*
}

\author{
Chen-Chi Chang \\ National United University, Miaoli, Taiwan
}

\begin{abstract}
Family history can be a very interesting research field which has not yet been much explored. The genealogy is one kind of digital archives. There are many researches focusing on the digitization of family history and genealogical material. There are three types of genealogy tourism in Hakka ethnic group, including homeland tourism, family temple names tourism, and common ancestor tourism. According to the genealogy curious and return intention to homeland, there are four kinds of ancestral tourists. The recognition of the role of technology and the increasing use of the internet for genealogy development has offered new opportunities to sell accommodation and other tourism-related products. The genealogy tourism marketing matrix has four alternatives of marketing strategies: well-developed genealogy tourism, enhance ancestral connection, improve tourism infrastructure, and potential genealogy tourism. Responding to this, this study proposed four key factors which are identified to have facilitated the development of genealogy tourism, including information communication technology, resources, search for identity, and postmodern forms of tourism. There are several challenging issues in linking genealogy and tourism including interpretation, marketing built genealogy, planning for genealogy, and the interdependencies between genealogy tourism and the Hakka cultural industry.
\end{abstract}

Keywords: genealogy tourism, digital archives, market opportunities, Hakka genealogy

\section{Introduction}

The modern tourism market seems to be increasingly characterized by a multiplicity of demand for alternative cultures, entertainments, and attractions, and stimulating new tourism segments (Novelli, 2007). It has long been recognized that cultural tourism develops rapidly within global movement societies and countries. Researchers recently have started to focus explicitly on tourism and cultural heritage management (Du Cros, 2001; Silberberg, 1995; Zeppel \& Hall, 1991). Cultural tourism business opportunities have been a pathway in bringing minority communities into mainstream tourism development (Sofield \& Li, 1998). One of the important forms of cultural tourism may be classified as "ethnic tourism". Ethnic tourism is defined as that form of tourism where the cultural exoticism of natives is the main tourist attractant (Van den Berghe, 1992). In advance, according to the previous study, there are two types of ethnic tourism. One of them is genealogy tourism (also refers to root tourism) and the other is tourism with the purpose of getting to know other people’s differing cultural background from an authentic approach (Csapó, 2012). The genealogy tourism market opportunities presented in this study confirm that niche tourism can be defined in relation to its multitude of factors interacting and responding to a changing tourism demand and market trends. The Hakka

\footnotetext{
* Acknowledgements: This paper was supported by the Ministry of Science and Technology of Taiwan under Grant MOST 103-2410-H-239-004-MY2.

Chen-Chi Chang, Ph.D., associate professor, Department of Culture Creativity and Digital Marketing, College of Hakka Studies, National United University. Email: kiwi@nuu.edu.tw.
} 
people are one branch of the Han Chinese who lives predominantly in the provinces of Taiwan, Guangdong, Jiangxi, and Fujian in China. The whole Hakka history is the Hakka migration history. The Hakka population in Taiwan is around 6.8 million people today. Hakka people comprise about $15 \%-20 \%$ of the population of Taiwan and form the second-largest ethnic group. The number of domestic and international distribution of Hakka is 656 million, of which 610 million domestic and 46 million foreign. The Hakka have immigrated to many regions worldwide, notably Taiwan, Suriname, India, Bangladesh, Malaysia, Singapore, Indonesia, Thailand, East Timor, and Burma. While certain niche segments, such as cultural heritage, sport and adventure tourism, are widely known and easily recognizable, there are others listed under newly born micro-niches, such as photographic, genealogy and research tourism. Genealogy (Zupu in Chinese) is the history of Chinese families. Genealogy has been widely used for the tracing of their lineages and history (Chang, Chao, \& Wu, 2013). Since Hakka is one of the Chinese ethnic minority groups, tracing of their lineages and family history is a powerful emotion for Hakka people.

\section{Genealogy Tourism}

Family history can be a very interesting research field which has not yet been much explored. The genealogy is one kind of digital archives. There are many researches focusing on the digitization of family history and genealogical material. In previous study, Liaw (2003) provided extensive discussions of genealogy, overview of genealogical documents reorganization, antiquarianism, as well as the genealogy of the contribution. As more and more people become interested in researching their family roots, this study presents new and exciting commercial opportunities. In the past, genealogy is the record of basic information about births, marriages, and deaths linked together to form a family tree. Writing the genealogy is a journey of discovery - if you have not started researching your family tree yet, you are missing out on what must be the world's fastest growing hobby (Taylor, 2002). Researching your family history is a journey of discovery that is not over until you have actually visited your ancestral homeland (Novelli, 2007). Recently, the tracing of our ancestors has become a major preoccupation - genealogy as one of the most popular subjects on the internet (Gilchrist, 2000). Genealogy tourism, also called personal heritage tourism (Timothy, 1997), roots tourism, ancestral tourism or Diaspora tourism, refers to "restless or halfway" populations who sojourn back to their homeland to engage in the re-making and de-making of their identities (Ross, 2010).

\section{Hakka Genealogy Development}

The Hakka people are one branch of the Han Chinese who lives predominantly in the provinces of Taiwan, Guangdong, Jiangxi, and Fujian in China (Xie, 2007). Hakka is one of the oldest Chinese ethnic groups. Hakka people have a strong preservation of the culture, heritage, particularly in the dialect. Instead of living in the same region, the history of the Hakka is one migration and conflicts with the people they lived around and competed with for land. There were many difficulties in migration of Hakkas. Hakkas have been recognized as not afraid of predicaments and courageous spirit. The reason for Hakkas special attention to the genealogy records is that they leave hometown frequently. Hakka genealogy contents include migration process of the family, genetic relationships, marital status, family instructions, and so on. The nature of Hakkas owes to ancestors. It will affect the emphasis on their genealogy. Hakka genealogy is an important part of Hakka culture. The family rules and regulations in the genealogy, which are the crystallization of their 
ancestors' philosophies and experiences of life, represent the values of the Hakkas (Li, 2006). Liaw (2003) also noted that there are important historical values of genealogy including economic, demographic, educational, ethnic and religious, etc. (Liaw, 2003). Nowadays, several studies indicated genealogy as the critical reference because of their potential to disentangle complex population histories (Kuhner, 2009; Meskill, 1970; Zatloukal \& Harvey, 2004). In the past, genealogy often consists of a family or a clan as a unit and writing in the paper. Various social and environmental factors, such as war, natural disasters, and migration, lead to the damage and disappearance of genealogies. Several sites offer the services of writing genealogy and providing offspring to find their ancestors, such as Ancestry.com (Ancestry, 2012) and Taiwan Genealogy Online (National Central Library, 2012).

\section{Business Opportunities of Shibi Hakka Homeland}

There are three types of genealogy tourism in Hakka ethnic group. First, homeland tourism, every family has the own homeland. Second, family temple names tourism, the Hundred Family Surnames is a classic Chinese text composed of common Chinese surnames. Every Hakka surname has one or more family temple names, usually is the famous place (homeland) of the family. Third, common ancestor tourism, the Hakka people trace descent from one common ancestor. New niche marketing strategy, like developing business opportunities of genealogy tourism services or taking advantage of ancestral resources produced by Hakka homeland, could with creative thinking arise over the traditional services of tourism industry. Genealogy is an important resource of ancestral tourism, as well as ancestral tourism is beneficial to develop genealogy. Hakka culture has high experience value, enjoying value, educational value, and scientific value in genealogy development, which was not only preserving ancient Hakka culture, but also integrating local cultural industry. Genealogy tourism in this study is defined as a visit to Hakka homeland partly or wholly motivated by the need to reconnect with family's ancestors or roots. Hakka homeland in China is the town of Shibi of Ninghua. Ninghua is a county of Sanming, in western Fujian Province, People's Republic of China, bordering Jiangxi to the west. The town of Shibi of Ninghua is well known as the cradle of the Hakka. Shibi bills itself as the cradle of the Hakkas for its place in Hakka history. Shibi Village of Ninghua County, Fujian Province, which is acclaimed as the homeland of Hakkas, the cradle of Hakkas, and the pilgrimage centre of the Hakkas all over the world, possesses a world-class standing and its Hakka culture has had a great influence upon the world (Luo, 2008). Shibi, Ninghua is the cradle and originating area of Hakka and is the common home of Hakka in the world. As the ancient field of Hakka, Shibi has rich Hakka culture resources, which are important resources of tourism development (Huang, 2011). Ancestral tourism is a growing and important niche market for Hakka homeland. With over 100 million people across the globe able to lay claim to Hakkas ancestry, the scope and potential of this market for Hakkas tourism is huge, and the good news is that there are real opportunities for businesses right across the country to benefit (Zhan, 2014). Hakka cultural tourist area is an important tourism area of Fujian Province. Hakka homeland culture is an important part of the tourist line in Northwest of Fujian Province. It has an important position and role of the cultural tourism development in Fujian Province (Yu, 2011). Since 1995, the leaders of overseas Hakka and all friends of the enthusiastic support participate actively in the World Hakka Ancestral Homeland Ancestor Worship Ceremony which has been successfully held for 20 years, attracting more than millions of Hakkas around the world. 


\section{The Ancestral Tourist Segments}

Tourist segmentation is a very popular and broadly accepted way of increasing market profitability (Dolnicar \& Leisch, 2003). Understanding the attractiveness of ancestral heritage to different tourist segments is a prerequisite to effective marketing strategy implementation. According to the genealogy curious and return intention to homeland, there are four kinds of ancestral tourists (see Figure 1). Firstly, return tourists, with high ethnic group identity, who are fully supportive of the genealogy tourism experience and have economic ability to return to their homeland. Secondly, supplementary ancestral tourists, with strong ethnic group identity, who have a strong intention to return, but have low ability to return. Maybe there is economic issue or distance. These tourists would consider participating in worship practices supported by the government. Thirdly, potential genealogy tourists, these tourists are lightly curious about the family history. They have low ethnic group identity, but with high purchase ability. Genealogy and family history writing platform can help them to know about their family and encourage them to return. Fourthly, incidental ancestral tourists, these tourists were lightly curious about their family history but have low ability to return. We need to introduce the ethnic group and family history to recall their ethnic identity. The recognition of the role of technology and the increasing use of the internet for genealogy development have offered new opportunities to sell accommodation and other tourism-related products.

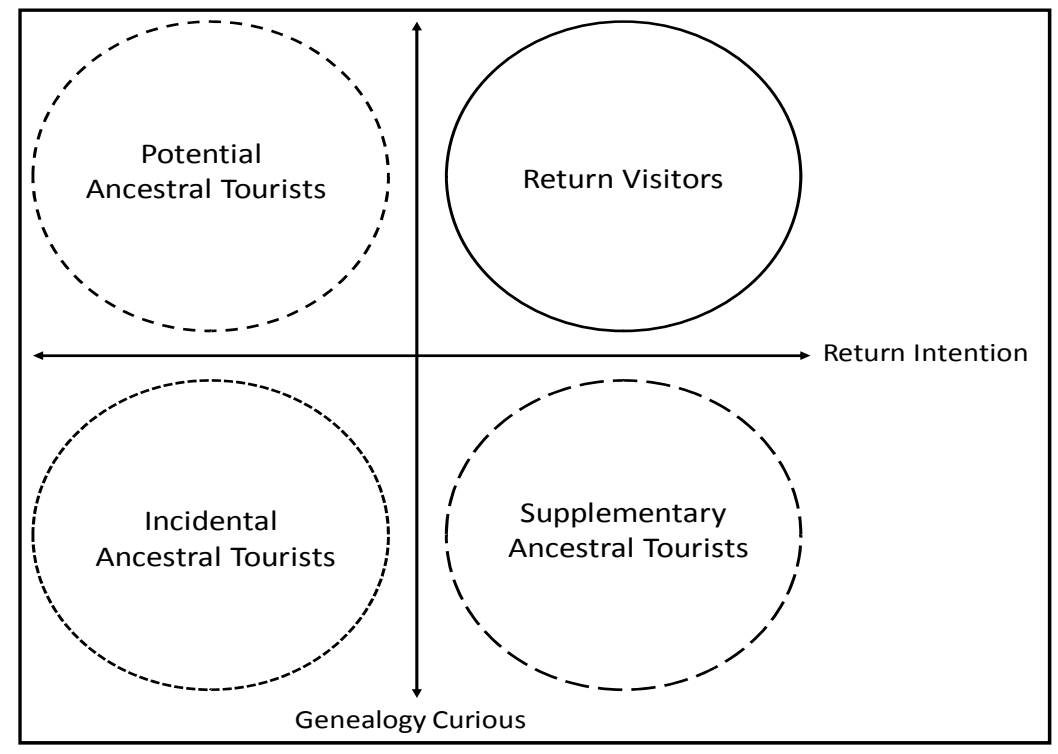

Figure 1. Ancestral tourist segments.

\section{The Genealogy Tourism Marketing Matrix}

The strategic marketing matrix for genealogy tourism makes travel agents and senior managers to think about the intersection of genealogical connection and tourism attraction. The genealogy tourism marketing matrix has four alternatives of marketing strategies: well-developed genealogy tourism, enhance ancestral connection, improve tourism infrastructure, and potential genealogy tourism. Responding to this, this study proposed four key enablers which are identified to have facilitated the development of genealogy tourism, including information communication technology, resources, search for identity, and postmodern forms of tourism (Novelli, 2007). 


\section{Information Communication Technology (Potential Genealogy Tourism)}

The role of the internet has enhanced the growth in family history research and information technology can be credited for simplifying writing genealogy (Clifford, 2001; Howells, 2001). It is easy to find the genealogy on the internet (Christian, 2002), and the recognition of the role of technology and the increasing use of the internet for genealogy development have offered new opportunities to sell accommodation and other tourism-related products.

\section{Resources (Improve Tourism Infrastructure)}

The growth in family history has been accelerated by the increasing provision of various key online resources. The substantial development aid, mainly used to improve tourism infrastructure and to provide job opportunities, shaped the fundamental incentive structure and had profound effects on the behavior of community members (Tai, 2007). Hakka genealogy tourism industry has been identified as a growth sector due to the fast growing economies in Asia. The key infrastructures such as hotels, restaurants, and museum assist the development of the tourism industry.

\section{Search for Identity (Enhance Ancestral Connection)}

Search for identity is a form of heritage tourism and a cultural component which can be used to make ethnic identity. In a sense the internet has enabled vicarious journeys to homelands and has provided a virtual sense of identity for the researcher. This virtual homecoming may provide a virtual reality experience but as such is more likely to provide a spur for the real thing (Brown, 2000).

\section{Postmodern Forms of Tourism (Well-Developed Genealogy Tourism)}

The role of heritage in postmodern tourism is examined, particularly built heritage, which is at the heart of cultural tourism (Nuryanti, 1996). Well-developed genealogy tourism is the completely postmodern form of tourism. The complex relationships between tourism and genealogy are revealed in the tensions between tradition and modernity. Despite globalization and the global diffusion of consumer capitalism, individuals continue to exercise strategies of personal identification (Hughes, 1995).

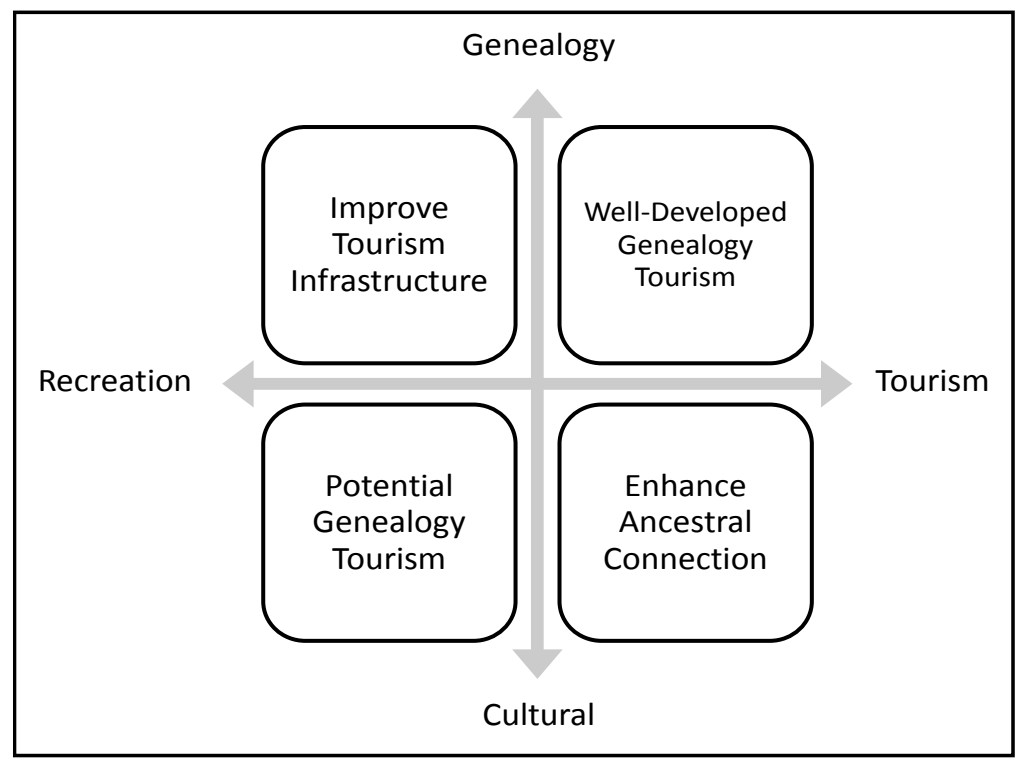

Figure 2. Genealogy tourism marketing matrix. 


\section{Discussion and Conclusions}

Considering then that the ancestral tourist is going back both spatially and emotionally to their roots, i.e., the starting place, the term "ancestral tourist" can at least be applied in academic discussion. The Scottish Executive (2000) identified four key elements in the development of genealogy tourism: (1) linking genealogy websites; (2) developing the promotional potential of genealogy tourism overseas; (3) introducing tactical direct marketing campaigns; and (4) promotion in specialist ex-pat publications. There are several challenging issues in linking genealogy and tourism, including: interpretation, marketing built genealogy, planning for genealogy, and the interdependencies between genealogy tourism and the Hakka cultural industry.

\section{References}

Ancestry. (2012). Retrieved from http://www.ancestry.com/

Brown, F. (2000). Tourism reassessed: Blight or blessing? London: Routledge.

Chang, C. C., Chao, R. M. C., \& Wu, T. Y. (2013). Hakka genealogical metadata principles and practicalities. Social Networking, 2(2), 57-62.

Christian, P. (2002). Finding genealogy on the internet. London: D. Hawgood.

Clifford, K. (2001). The complete beginner's guide to genealogy, the internet, and your genealogy computer program. Genealogical Publishing Company.

Csapó, J. (2012). The role and importance of cultural tourism in modern tourism industry. In M. Kasimoglu, \& H. Aydin (Eds.), Strategies for tourism industry - Micro and macro perspectives (pp. 201-232). Rijeka: InTech Open Access Publisher.

Dolnicar, S., \& Leisch, F. (2003). Winter tourist segments in Austria: Identifying stable vacation styles using bagged clustering techniques. Journal of Travel Research, 41(3), 281-292.

Du Cros, H. (2001). A new model to assist in planning for sustainable cultural heritage tourism. International Journal of Tourism Research, 3(2), 165-170.

Gilchrist, J. (2000). Roots systems: Technology is making DIY genealogy simple. Retrieved from http://archiver.rootsweb.ancestry.com/th/read/SCT-FIFE/2000-03/0952914772

Howells, C. (2001). Cyndi's list: A comprehensive list of 70,000 genealogy sites on the internet (Vol. 2). Genealogical Publishing Company.

Huang, X. Z. (2011). The status of Hakka culture development and utilization of travel resources in Sanming and its countermeasures. Journal of Sanming University, 28(4), 62-66.

Hughes, G. (1995). Authenticity in tourism. Annals of Tourism Research, 22(4), 781-803.

Kuhner, M. K. (2009). Coalescent genealogy samplers: Windows into population history. Trends in Ecology \& Evolution, 24(2), 86-93.

Li, X. Y. (2006). Values reflected in the family rules and regulations of the Hakka genealogy. Journal of Guangxi University for Nationalities, 28(3), 77-80.

Liaw, C. L. (2003). The Chinese genealogy. Nantian Shuju Publishing Company.

Luo, J. H. (2008). On the world-class quality and development of the tourism resources of Hakka hometown Ninghua. Journal of Sanming University, 1, 95-100.

Meskill, J. M. (1970). The Chinese genealogy as a research source. In M. Freedman (Ed.), Family and kinship in Chinese society (pp. 139-161). Stanford: Stanford University Press.

National Central Library. (2012). Taiwan memory. Retrieved from http://memory.ncl.edu.tw/tm_cgi_test/hypage.cgi?HYPAGE=about_tm_e.hpg

Novelli, M. (2007). Niche tourism. Routledge.

Nuryanti, W. (1996). Heritage and postmodern tourism. Annals of Tourism Research, 23(2), 249-260.

Ross, S. L. (2010). Transformative travel: An enjoyable way to foster radical change. ReVision, 32(1), 54-61.

Scottish Executive. (2000). A new strategy for Scottish tourism. Scottish Executive, Edinburgh.

Silberberg, T. (1995). Cultural tourism and business opportunities for museums and heritage sites. Tourism Management, 16(5), 361-365. 
Sofield, T. H. B., \& Li, F. M. S. (1998). Tourism development and cultural policies in China. Annals of Tourism Research, 25(2), 362-392.

Tai, H. S. (2007). Development through conservation: An institutional analysis of indigenous community-based conservation in Taiwan. World Development, 35(7), 1186-1203.

Taylor, C. (2002). Genealogy: No ordinary journey. Scotland Vacation Planner 2003. Great Britain: VisitScotland and British Tourist Authority.

Timothy, D. J. (1997). Tourism and the personal heritage experience. Annals of Tourism Research, 24(3), 751-754.

Van den Berghe, P. L. (1992). Tourism and the ethnic division of labor. Annals of Tourism Research, 19(2), $234-249$.

Xie, J. X. (2007). The Hakkas whose roots are in central plains. Journal of Huanghe S\&T University, 9(3), 15-19.

Yu, M. Z. (2011). RMP analysis of Shibi Hakka Hometown in Ninghua and development of tourism product. Journal of Sanming University, 28(1), 62-66.

Zatloukal, K. C., \& Harvey, N. J. A. (2004). Family trees: An ordered dictionary with optimal congestion, locality, degree, and search time. Proceedings of the Fifteenth Annual ACM-SIAM Symposium on Discrete Algorithms (pp. 308-317).

Zeppel, H., \& Hall, C. M. (1991). Selling art and history: Cultural heritage and tourism. Journal of Tourism Studies, 2(1), 29-45.

Zhan, T. D. (2014). 20th world Hakka ancestral homeland of ancestor worship ceremony held in Ninghua. Retrieved from http://www.smnet.com.cn/xwpd/mingsheng/201410/t20141016_200292959.htm 